Jaka Kovač, Andraž Legat, Bojan Zajec, Tadeja Kosec, Edvard Govekar,

Detection and characterization of stainless steel SCC by the analysis of crack related acoustic emission,

Ultrasonics,

Volume 62,

2015,

Pages 312-322,

ISSN 0041-624X.

(C) 2015. This manuscript version is made available under the CC-BY-NC-ND 4.0 license http://creativecommons.org/licenses/by-nc-nd/4.0/

Link to published article:

http://www.sciencedirect.com/science/article/pii/S0041624X15001523

DOI: https://doi.org/10.1016/j.ultras.2015.06.005 


\title{
Detection and characterization of stainless steel SCC by the analysis of crack related acoustic emission
}

Jaka Kovača

Andraž Legat ${ }^{a}$

Bojan Zajec

Tadeja Kosec ${ }^{a}$

Edvard Govekar ${ }^{\mathrm{b}, \text { * }}$

edvard.govekar@fs.uni-lj.si

aSlovenian National Building and Civil Engineering Institute, Dimiceva 12, SI-1000 Ljubljana, Slovenia

'Faculty of Mechanical Engineering, University of Ljubljana, Askerceva 6, SI-1000 Ljubljana, Slovenia

*Corresponding author. Tel.: +38614771 606; fax: +38614771651.

\begin{abstract}
In the paper the results of the acoustic emission (AE) based detection and characterization of stresscorrosion cracking (SCC) in stainless steel are presented. As supportive methods for AE interpretation, electrochemical noise, specimen elongation measurements, and digital imaging of the specimen surface were used. Based on the defined qualitative and quantitative time and power spectra characteristics of the AE bursts, a manual and an automatic procedure for the detection of crack related AE bursts were introduced. The results of the analysis of the crack related AE bursts indicate that the $\mathrm{AE}$ method is capable of detecting large scale cracks, where, apart from intergranular crack propagation, also some small ductile fractures occur. The sizes of the corresponding ductile fracture areas can be estimated based on a relative comparison of the energies of the detected AE bursts. It has also been shown that AE burst time and power spectra features can be successfully used for the automatic detection of SCC.
\end{abstract}

Keywords: Acoustic emission; Stress-corrosion cracking; Signal processing; Spectral analysis

\section{Introduction}

Stress-corrosion cracking (SCC) is a dangerous localized process of metal material degradation. It can cause the initiation and propagation of cracks in metal parts by the combined action of mechanical stress and corrosion reactions[1,2], and may lead to the unexpected failure of 
metal structures with severe consequences [1,2]. Stress-corrosion cracking occurs in specific combinations of three essential conditions: a sufficient level of tensile stress or strain, an aggressive electrolyte, and a susceptible material. Although the general conditions for SCC occurrence are known, the process is very difficult to predict, especially because of its nonstationary nature.

Regarding crack propagation, two different modes of SCC can be distinguished: intergranular SCC (IGSCC), where cracks advance along crystal grain boundaries, and transgranular SCC (TGSCC), where cracks advance through the crystal grains. Although the nature of neither of these proposed physical mechanisms has not yet been clearly confirmed, it is known that IGSCC process is smoother and therefore more difficult to detect.

Numerous investigations have been performed into the use of acoustic emission (AE) analysis for the detection and characterization of different types of corrosion processes, such as uniform corrosion [3,4], crevice corrosion [5,6], erosion corrosion [7], and pitting corrosion [3,6,8-17], and $\mathrm{AE}$ analysis seems to be very promising for the detection and characterization of stress-corrosion cracking [18-30,10,31-4210,18-42]. The reasons for using AE for SCC characterization are its ability AE to detect small energy relaxations such as crack initiation and growth, and its ability to detect the development of defects inside the material in the case of limited access to the structure being investigated [18]. The characterization of SCC is usually based on the analysis of detected AE bursts, because cracking events are known to generate characteristic AE bursts [18]. In the case of using AE signal analysis for characterization of SCC, it is essential to have good knowledge about the possible sources of detected AE waves, as well as about acoustic wave propagation through the material. In case of the SCC of stressed metal parts, several possible sources of AE can be identified $[18,19]$. The main source of AE is the propagation of stress-corrosion cracks, and the subsequent plastic deformation of the material which occurs. Plastic deformations can occur at or in front of a crack tip, but can be also the consequence of exceeding the yield strength of the material because of the reduced cross-section of the specimen due to an existing crack. Besides the above-mentioned sources of AE waves during SCC, some authors have suggested that even electrochemical processes could be a source of AE [19], although the amplitudes of AE bursts are much lower than in the case of mechanical deformations. On the microscopic scale, various possible sources of AE have been be identified [18]: cleavage micro fracture, the brittle intergranular propagation of micro fractures, cracking at inclusions, and micro void coalescence which can lead to ductile fracture. 
In the past $\mathrm{AE}$ has been applied for the investigation of SCC on different metals and alloys: e.g. on brass alloy [20-22], high strength steels [22-26], and inconel alloys [27], as well as on stainless steel $[28-30,10,31-4210,28-42]$. Focusing on the research into the SCC of stainless steel which is frequently used in mechanical structures, Jones et al. [28 30,1010, 2839???] successfully detected transgranular (TGSCC) cracking, but their results concerning intergranular cracking (IGSCC) were not so conclusive. It was assumed that the transgranular fracture surfaces in the predominant intergranular cracks were the result of ligaments that fractured behind the advancing intergranular crack front, and that these fractures were related to the detected AE activity. Other authors, in later research, came to similar conclusions [31-33], i.e. TGSCC could be successfully detected by AE, but that the detection of IGSCC was less reliable and more difficult. From comparisons of IGSCC and TGSCC experiments, it was determined that measured AE activity during the propagation of TGSCC is generally one order of magnitude higher than that measured during IGSCC propagation [31]. On the other hand, the mean values of the amplitude and rise time of the AE signals registered during both processes were found to be similar [31]. AE activity was measured during various stages of SCC: in most cases researchers found that the it was the highest just beyond the yield point, and before final fracture [34]. In some other studies [32,33,35-37] it was indicated that individual AE activity could be related to crack initiation, crack propagation and final failure.

In order to obtain additional information about the relationship between $\mathrm{SCC}$ and $\mathrm{AE}$, various other methods, including electrochemical noise (EN), tensile force and elongation measurements, and digital imaging [32,33,36-42] have been used simultaneously with the acoustic emission method. In the work [38] electrochemical potential was related to the characteristics of acoustic emission signals. Electrochemical noise (EN) has been the most frequently used complementary method to $\mathrm{AE}[32,33,36,37,39-42]$. In this method the EN potential signal is compared to the number of detected AE bursts, and their characteristics are related to SCC [39]. In the latter research spectral analysis of AE signals was successfully applied in order to differentiate between pitting corrosion and SCC. In other research [40], it was proposed that AE bursts were related to falling-off of surface crystal grains, which followed by with EN detected dissolution of crystal grain boundaries. In [41,42] AE was also simultaneously used with $\mathrm{EN}$, and the observed increase in AE activity and fluctuations in EN signals were related to SCC, although the exact relation between the AE bursts and the EN signals was not determined. The latter was also performed in a recent investigation, where AE bursts and EN current transients were related to the cracking process [36,37]. It was proposed that simultaneous AE bursts and EN 
transients are caused by the ductile fracture of ligaments which, at the more resistive grain boundaries, stayed behind the intergranular advancing crack tip.

Our research work bases on the use of different physical and electrochemical techniques for monitoring and characterizing stress corrosion cracking phenomena. Our experiments were presented in detail in the work ofJ.Kovač et al. [36,37], where different monitoring techniques, such as electrochemical noise, elongation, acoustic emission and digital image correlation were evaluated as techniques for detecting SCC on stainless steel in sulphate media. In the current study, the same measurements are interpreted with strong focus on the signals achieved by acoustic emission.

In the following sections an experimental system for the monitoring of AE during the SCC process is presented, and the results of performed SCC experiments are described. The experimental system included simultaneous measurements of EN, specimen elongation, and digital imaging and acoustic emission measurements of the specimen surface. In order to achieve the reliable detection of SCC related AE signals during the SCC experiment, filtering methods of the AE signals which rely on the qualitative and quantitative time and power spectra characteristics of AE bursts have been proposed, and are described at the end of the second chapter. The analysis of the crack related acoustic emissions signals is given in relation to intergranular and ductile fracture and the comparison of the energies of the $\mathrm{AE}$ bursts in relation to different type of fracture is discussed. Also, the possible automatic detection of SCC by the use of AE, is presented. Based on a relative comparison of the energies of the detected AE bursts, the sizes of the corresponding ductile fracture areas have been estimated. Preceding the conclusions, the possibilities for the automatic detection of SCC, using the proposed AE characteristics, are presented.

\section{The experimental system and $\mathrm{AE}$ preprocessing}

In the following text an experimental system for the $\mathrm{AE}$ based monitoring and detection of SCC is presented, including a description of the measuring equipment, the SCC experiments, the specimen material used, and the specimen preparation. In order to distinguish between SCC related $\mathrm{AE}$ and noisy signals caused by other sources, in the second part of this section the preprocessing of the detected AE signals is explained in more detail.

\subsection{The experimental system}

The experimental system, i.e. the corrosion cell which was designed for the detection of AE during SCC degradation processes on specimens, is shown schematically in Fig. 1. In order to provoke SCC during the experiment, the specimens were loaded by a preselected static tensile force $F$. For the detection of AE, two equal wide-band piezoelectric based sensors with an 
operating frequency in the range of $20 \mathrm{kHz} \_1 \mathrm{MHz}$ were used. The peak sensitivity of the sensors was $45 \mathrm{~dB}$ versus reference $1 \mathrm{~V} /(\mathrm{m} / \mathrm{s})$ and $-85 \mathrm{~dB}$ versus the reference $1 \mathrm{~V} / 1 \mu \mathrm{bar}$. The sensors were fixed symmetrically to the semi-circular notch out of the corrosion cell, one to the top and the other to the bottom of the specimen, Amplification of the detected signals was set to $40 \mathrm{~dB}$. The signals were transferred to a PCI-2 based AE A/D monitoring system, where the AE signals were sampled at a frequency of $1 \mathrm{MHz}$. In order to increase the AE signal to noise ratio a high-pass frequency filter with a cut-off frequency of $1 \mathrm{kHz}$ and a low-pass frequency filter with a cut-off frequency of $1 \mathrm{MHz}$ were used.

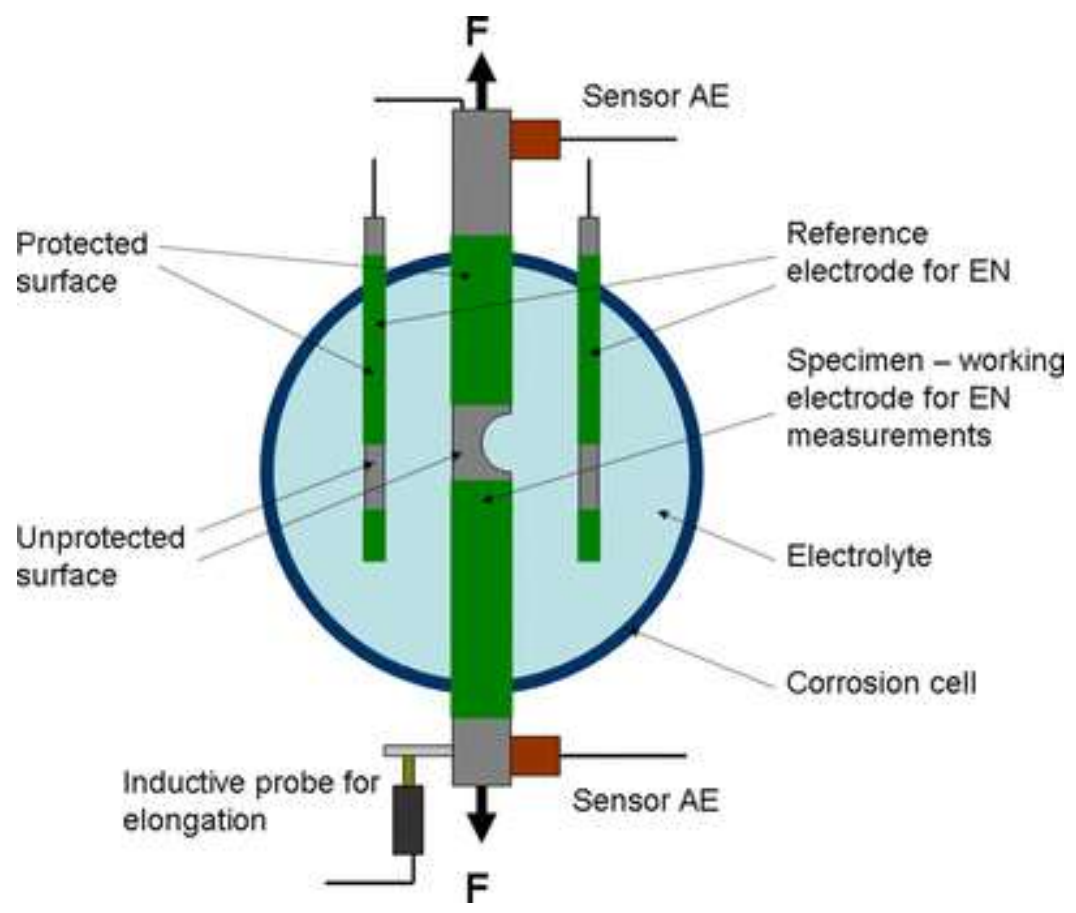

Fig. 1 The experimental corrosion cell set up.

For the comprehensive SCC characterization and interpretation of SCC related AE signals the corrosion cell was equipped with a set of two auxiliary reference electrodes for electrochemical noise (EN) measurements. The exposed surface of each reference electrode is equal to that of working electrode and measures $50 \mathrm{~mm}^{2}$ (Fig. 1). The experimental setup was also equipped with a sensor for measurements of specimen elongation, and a system for the digital imaging of the specimen surface. The EN data were collected using a sampling rate of $10 \mathrm{~Hz}$, with a resolution of the measured current of $30 \mathrm{pA}$, and a resolution of the measured potential of $15 \mu \mathrm{V}$. Digital imaging of the specimen surface was performed by means of a digital CCD camera. The rate of image capture was one image per minute. Specimen elongation was measured by an inductive probe with a sampling frequency of $5 \mathrm{~Hz}$, and a resolution of $0.4 \mu \mathrm{m}$. 
The specimens used in the experiment were made of austenitic stainless steel of type AISI 304. The plates had a thickness of $2 \mathrm{~mm}$, and were $12 \mathrm{~mm}$ wide and $280 \mathrm{~mm}$ long. For the purpose of crack initiation and location, they had semi-circular notches with a radius $8 \mathrm{~mm}$ at the midlength. Distance between the notch center and the center of each AE sensor was approximately $100 \mathrm{~mm}$. In order to increase the susceptibility of the material to IGSCC, the material was sensitized before the specimens were produced. For this purpose the steel was heated to $1050{ }^{\circ} \mathrm{C}$ in a vacuum, maintained at this temperature for $1 \mathrm{~h}$, and quenched in oil. It was then re-heated to $650{ }^{\circ} \mathrm{C}$ in a vacuum, maintained at this temperature for $24 \mathrm{~h}$, and cooled down to room temperature in the open air. After sensitization the obtained microstructure of the material was austenitic, with no dominant orientation of the crystal structure. The yield stress of the tested material was determined to be $230 \mathrm{MPa}$, and the ultimate tensile stress $650 \mathrm{MPa}$. In order to develop intergranular SCC [1,2], the specimen was sealed inside the corrosion cell, which was filled with an aqueous solution of $0.5 \mathrm{M}$ sodium thiosulphate $\left(\mathrm{Na}_{2} \mathrm{~S}_{2} \mathrm{O}_{3}\right)$ at $20 \stackrel{\circ}{ }{ }_{-}^{\circ} \mathrm{C}$.

During the experiment the specimens were loaded by the preselected static tensile force $F$. The loading machine stood on a rubber support plate, which damped unwanted vibrations and also enabled electrical isolation from the surrounding. Several experiments were performed, where the specimens were loaded up to different constant load levels up to $50 \%$ of the material's ultimate tensile strength. In some cases the load level was increased during experiment. The performed experiments, with the applied load levels expressed as a percentage of the specimens' tensile strength, are presented, together with the changes in the loading, and the time to specimen failure, in Table 1.

Table 1 List of the performed experiments, the applied load levels, and the time of the specimen failure.

\begin{tabular}{|l|l|l|}
\hline No. & Applied stress $\sigma$ (at time $t)$ & $\begin{array}{c}\text { Time to failure of the } \\
\text { specimen }\end{array}$ \\
\hline 1 & yielding strength $R_{\mathrm{p} 0.2}=35 \%$ tensile strength $R_{\mathrm{m}}(0 \mathrm{~h})$ & \\
\hline & & \\
\hline $45 \%$ of the tensile strength $R_{\mathrm{m}}(15 \mathrm{~h})$ & \\
\hline $50 \%$ of the tensile strength $R_{\mathrm{m}}(25 \mathrm{~h})$ & \\
\hline 2 & & \\
\hline
\end{tabular}




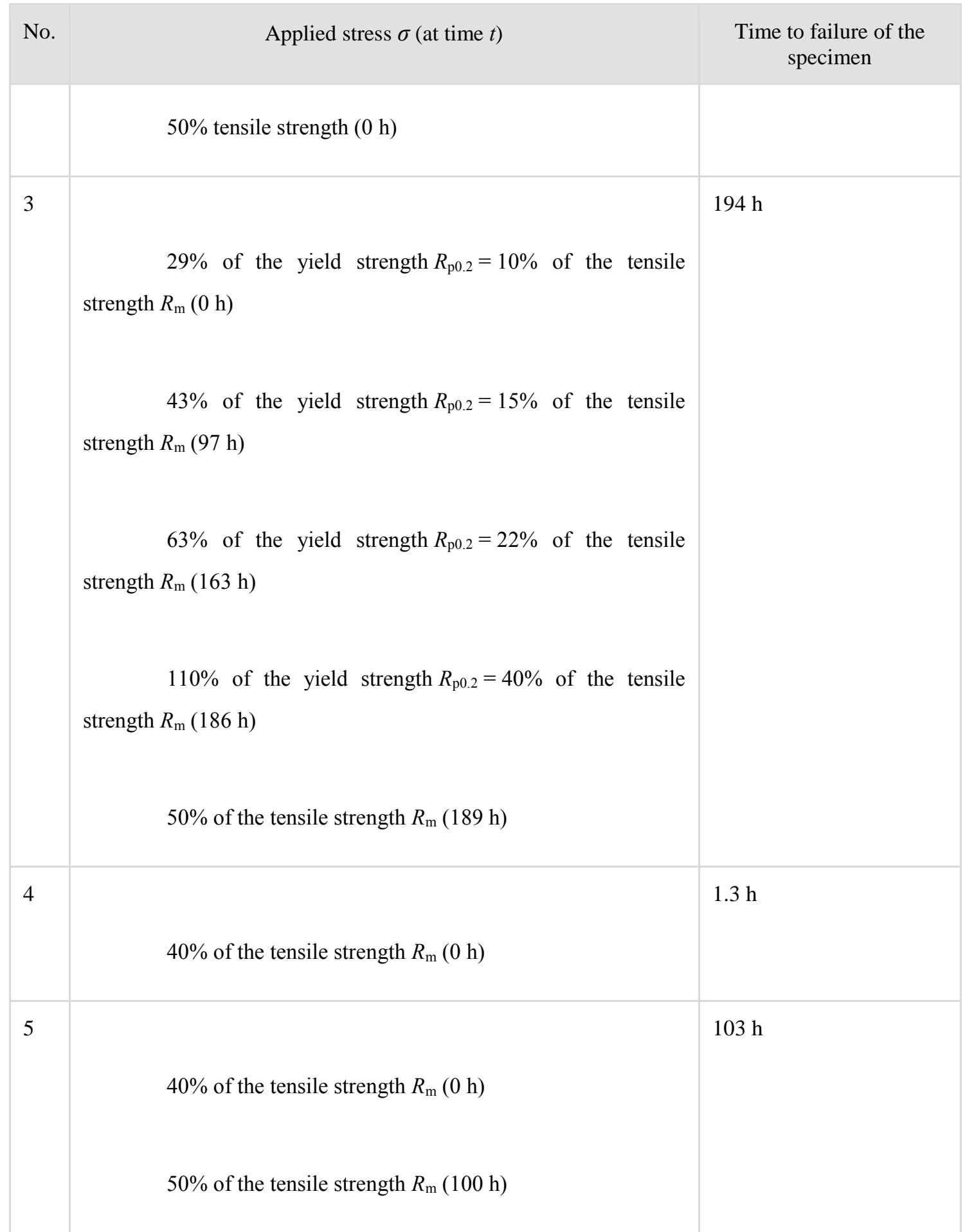

\subsection{AE signal detection and preprocessing}

For the continuous monitoring of AE during the SCC experiment, the maximum amplitude and the cumulative number of AE bursts related to the SCC process were applied. For this purpose the SCC related AE signals needed to be properly detected during the SCC experiment. In order to achieve this aim, a suitable AE signal trigger level for the detection of AE potentially related to 
the SCC process has to be defined. For this reason the instrumental noise level and other possible sources of acoustic noise were inspected during SCC experiments by $10 \mathrm{~min}$ of pre-monitoring of the $\mathrm{AE}$. The level of the continuous noise was determined to be around $27 \mathrm{~dB}$ with respect to $1 \mu \mathrm{V}$. Additionally, some individual AE bursts were detected. The amplitudes of these bursts were in most cases $(\sim 80 \%)$ below $35 \mathrm{~dB}$. For this reason the trigger level for the $\mathrm{AE}$ signal acquisition used in the experiments was set to $35 \mathrm{~dB}$ with respect to $1 \mu \mathrm{V}$.

Using the above-defined AE signal trigger level the experiments with the tensile stress loaded specimens were performed. The AE was monitored during the SCC experiment from the time of the initial loading of the specimen up to the time of the specimen failure. Whenever the preset trigger level was exceeded, the AE signal was acquired for $5 \mathrm{~ms}$ and stored for further analysis. Acquisition of corresponding $\mathrm{EN}$ and specimen elongation was performed simultaneously. In general, as evident in Fig. 2, two types of detected AE signals were observed: (1) typical AE transient burst signals with a characteristic abrupt amplitude increase followed by an approximately exponential decrease in the oscillating amplitudes and (2) AE signals with more constant oscillating amplitudes. AE bursts with an abrupt increase in amplitude (i.e. with an amplitude rise time of $t_{\mathrm{iAE}}<0.2 \mathrm{~ms}$ ), followed by an approximately exponential decrease (i.e. an amplitude decay time of $t_{\mathrm{dAE}}>0.4 \mathrm{~ms}$ ) were observed during crack growth (Fig. 2a and b) and specimen failure (Fig. 2c). On the other hand, AE signals without decaying burst characteristics were related to noise. They were either observed during the pre-cracking period (d), or caused by mechanical loading of the specimen (e), or some other unknown noise related source during crack growth (f). The failure did not result in a single AE burst but in a number of them that occurred within a very short time. Fig. 2c represent a typical AE burst during failure, however there were also bursts with much higher amplitude (up to $10 \mathrm{~V}$ ). No signals with such large amplitude were detected during the prior (slow) crack growth. 

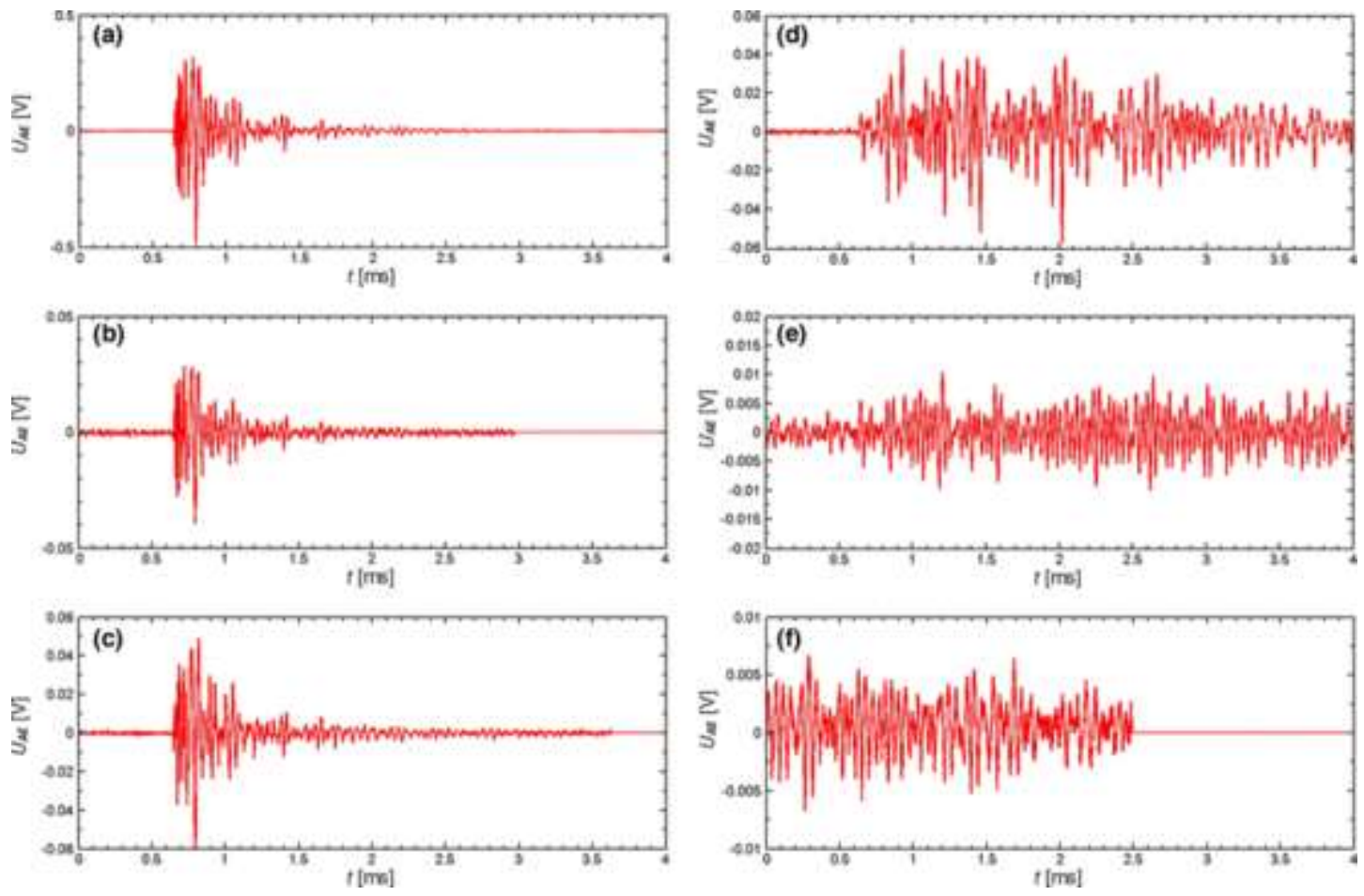

Fig. 2 Examples of different detected AE signals detected: (a) and (b) during crack propagation, (c) during failure of the specimen, (d) before the cracks were developed, (e) during loading of the specimen, (f) the AE noise signal, detected during crack propagation.

In Fig. 3 power spectra of the AE signals shown in Fig. 2 are presented in the frequency range from 0 to $250 \mathrm{kHz}$. From these spectra it can be seen that the crack related AE signals (shown in the left hand panel) have different power spectra characteristics than those corresponding to the crack non related AE signals (shown in the right hand panel). In more detail, it can be observed that the crack related AE signals occupy a relatively larger part of the power distribution in the frequency band above $50 \mathrm{kHz}$, in comparison to the non crack related AE signals. As can be seen from the right hand panel of Fig. 3, the power of the noise and non crack related AE signals is concentrated in the frequency band below $50 \mathrm{kHz}$. 

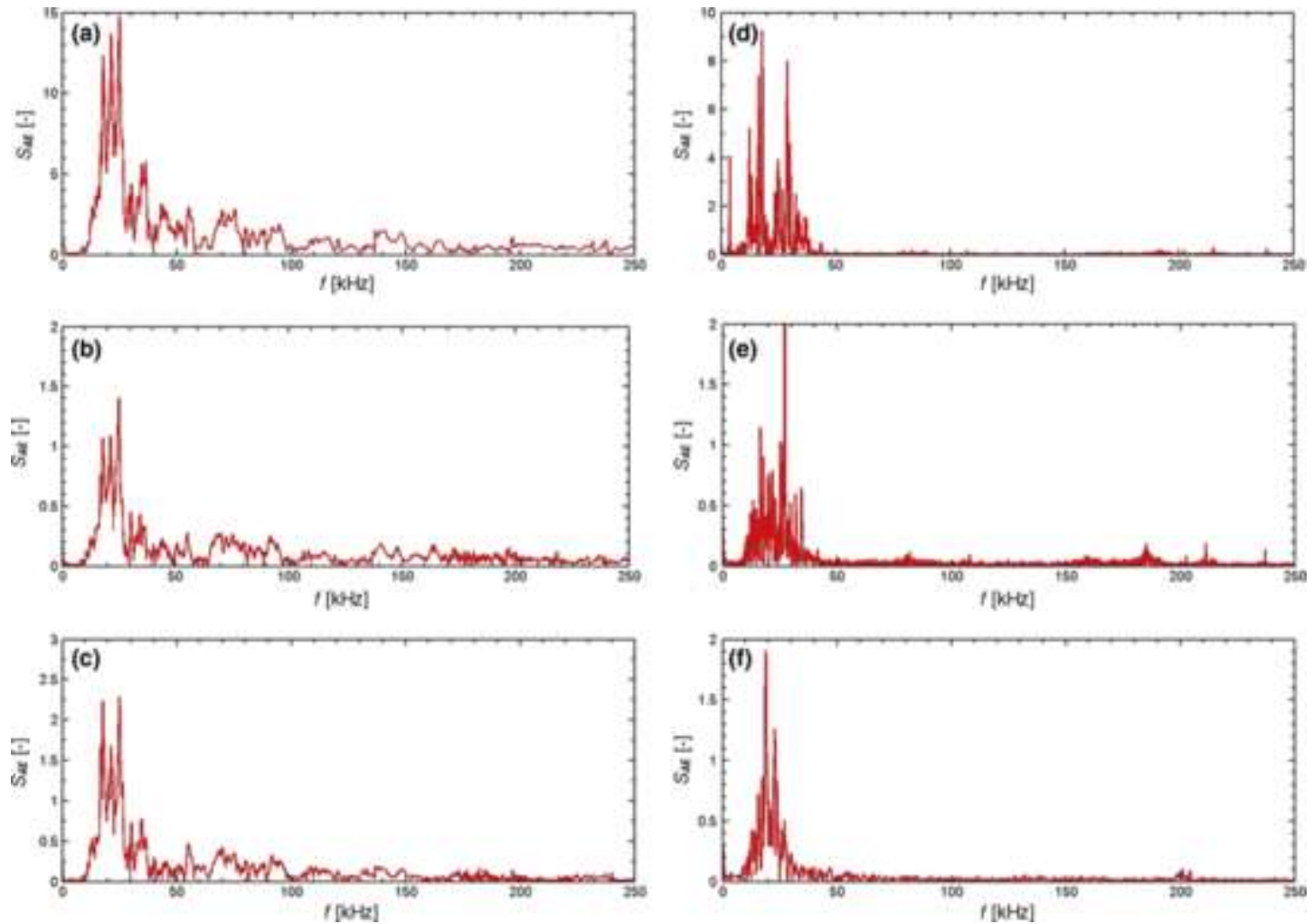

Fig. 3 Frequency spectra of the AE signals presented in Fig. 2: (a) and (b) detected during crack propagation, (c) detected during failure of the specimen, (d) detected before the cracks were developed, (e) detected during loading of the specimen, (f) an AE signal due to noise, detected during crack propagation.

During each of the performed experiments (Table 1) an extended set of AE signals was acquired. In order to further analyze and characterize SCC process by means of AE, it was necessary to select AE bursts which had presumably been caused by events related to SCC. On the basis of the above observed characteristics of AE signals in time and frequency space, two different procedures of noise signals filtering were proposed, with the aim of selecting the SCC process related AE signals from the complete set of acquired AE signals. The filtering procedures are presented schematically in the block diagram shown in Fig. 4. The left branch of the block diagram presents manual filtering of the AE signals, based on the visually observed AE waveform characteristics, whereas in the right branch of the block diagram an automatic, a method for AE signal amplitude and average frequency based filtering is presented. In the visual inspection based procedure the signals detected during the performed change of specimen loading are first eliminated. Further in the procedure all signals that do not poses the previously described characteristic waveform of an exponentially decaying burst are eliminated. 
Filtering of AE signals

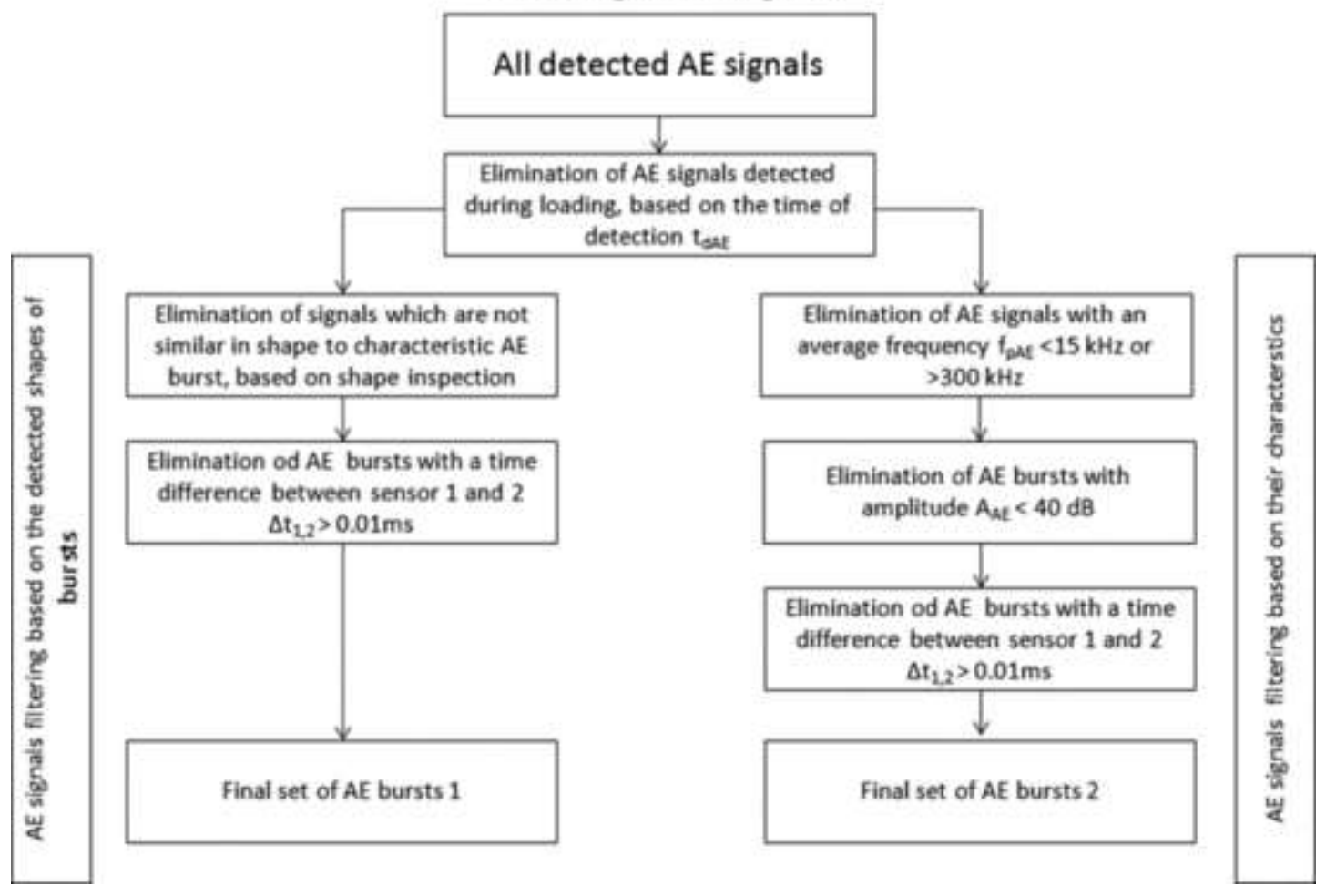

Fig. 4 Scheme of the procedures for filtering of the AE signals - (left) manual, visual inspection based, (right) automatic signal characteristic based.

As a further additional criterion, the difference in the time of detection $\Delta t_{1,2}$ of AE with both symmetrically placed sensors is used. By means of this criterion the AE signals of both sensors that were not detected at approximately the same time were eliminated. This is because, due to the symmetry of the specimen and the placing of the AE sensors, the relevant signals should arise from the same spot, i.e. from the gauge section of the specimen. For this purpose a time difference $\Delta t_{1,2}=0.01 \mathrm{~ms}$ was used. Taking into account a velocity of wave propagation of $5000 \mathrm{~m} / \mathrm{s}$, this difference of $\Delta t_{1,2}$ corresponds to a spatial difference of approximately $5 \mathrm{~cm}$, which is twice the difference in the distance between one sensor and cracking spot. Performing the described procedure, a set of AE bursts (the final set of AE bursts 1 shown in Fig. 4), which were most likely caused by crack propagation, was obtained. However, in the case of a large number of detected AE signals, this procedure is unpractical and excessively time-consuming. For this reason an automatic procedure for the selection of SCC related AE signals was developed, based on the time and frequency characteristics of the AE signals, as described below.

The automatic procedure of the filtering of the AE signals is presented in the right branch of the block diagram shown in Fig. 4. As in the case of the visual inspection based method, the signals detected during any change in the specimen loading are first eliminated. The criterion for 
the performing of this step automatically is the detection time which corresponds to the time of the performed specimen loading. Further elimination of the AE signals associated with noise is done by using the average $\mathrm{AE}$ signal frequency $f_{\mathrm{pAE}}$, which was empirically defined as a number of amplitude oscillations per time of the AE signal duration [18]. All the detected AE signals with average frequencies $f_{\mathrm{pAE}}$ below $15 \mathrm{kHz}$ and above $300 \mathrm{kHz}$ were eliminated. Signals with maximum amplitude below $40 \mathrm{~dB}$ were also eliminated from the obtained set of signals. The criteria for the used range of average frequencies and for the amplitude threshold for the elimination of noise signals were selected based on the experimentally observed differences in characteristics between the noise and crack related AE signals. In the final step of the automatic filtering procedure, those signals of the two AE sensors which were not detected at approximately the same time were also eliminated. The resulting final set of AE signals consists of detected characteristic exponentially decaying AE bursts, which were most likely caused by crack propagation.

Use of the two described procedures for the filtering of noise signals, i.e. the procedure based on visual inspection and the automatic procedure, resulted in very similar sets of final AE bursts. The difference between the number of AE bursts in the obtained final sets was, in the case of all of the performed experiments less than 10\%. By means of a comparison between the sets of selected AE signals, it was observed that, in general, the first visual inspection based procedure has a tendency to select some additional bursts with amplitudes of less than $40 \mathrm{~dB}$.

\section{Results and discussion}

In this section, the basic quantitative characteristics of the SCC related AE bursts, for the selected SCC experiment, are presented. The maximum amplitude of the detected AE bursts $A_{\mathrm{AE}}$, as well as their cumulative number $N_{\mathrm{AE}}$, their energy $E_{\mathrm{AE}}$, their duration time $t_{\mathrm{AE}}$, and their average frequency $f_{\mathrm{PAE}}$ were used as the quantitative characteristics of the measured $\mathrm{AE}$. The $\mathrm{AE}$ analysis based observations are compared with the results of supplementary SCC detection and characterization methods in order to confirm their validity. Furthermore the sizes of the areas of ductile fracture generated during the SCC process, as estimated from the AE data, are described and discussed. Finally, the results of the automatic detection of SCC based on the two extracted AE signal features are presented.

\subsection{AE signal based monitoring of SCC}

The results of AE signal based monitoring and characterization of SCC for a selected typical experiment - Experiment No. 1 (see Table 1) are presented in_Fig. 5. In Fig. 5a and b the stress applied to the specimen and the corresponding characteristics of the AE signals detected during the experiment are shown over a particular time interval of the experiment $[10,30]$ h. The 
presented time interval[10,30]h includes the performed change in the load applied to the specimen, the observed crack initiation, crack propagation and specimen failure. From the presented change over time of the stress due to the specimen load, as shown in Fig. 5a, it can be seen that, after the first initial constant load, the load was changed twice: the first load change was made after approximately $15 \mathrm{~h}$ and the second such change after approximately $25 \mathrm{~h}$. The maximum amplitudes $A_{\mathrm{AE}}$ (green circles) and the cumulative number $N_{\mathrm{AE}}$ of $\mathrm{AE}$ bursts (shown by a solid red line) were used as quantitative characteristics of the measured $\mathrm{AE}$ bursts. From the $\mathrm{AE}$ characteristics which are presented in Fig. $5 \mathrm{~b}$ it can be seen that only two AE bursts, most likely caused by external noise, occurred during the first loading phase. A larger number of AE bursts, presumably related to the SCC process, occurred during the maximum specimen load, at the very end of the experiment.
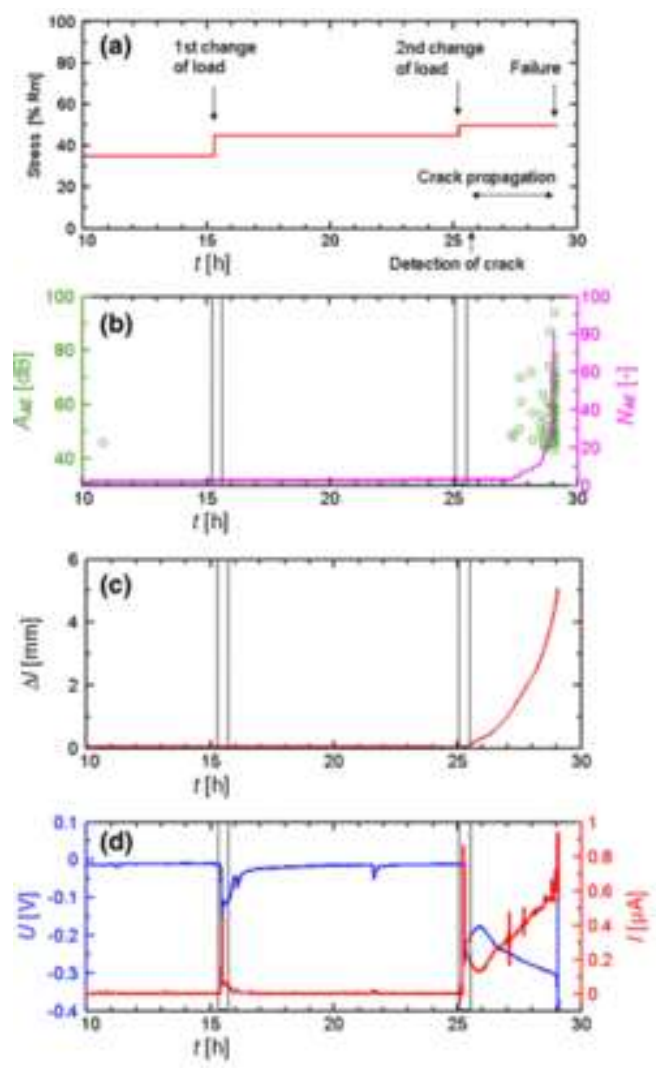
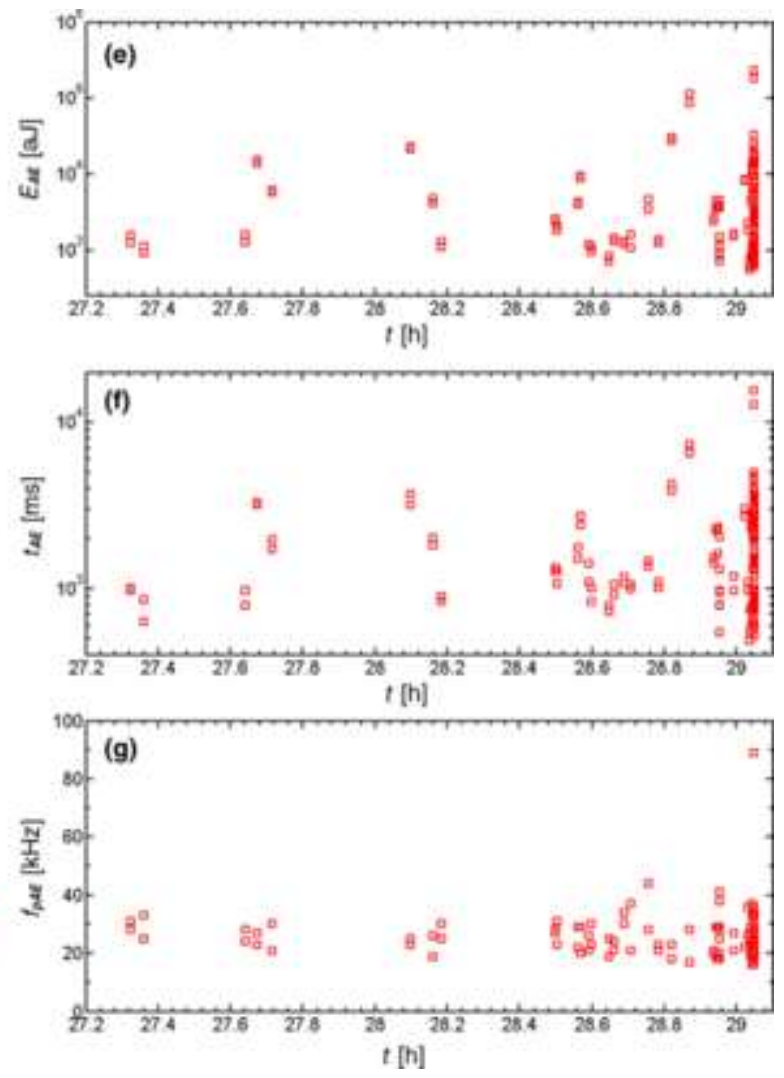

Fig. 5 The results of experiment No. 1. The left hand panel presents the results over the selected time interval of the experiment [10,30] h: (a) the change in the applied stress over time, (b) the maximum amplitude $A_{\mathrm{AE}}$ and cumulative number $N_{\mathrm{AE}}$ of the AE bursts, (c) the measured elongation of the specimen $\Delta l$, and (d) the potential $U$ and current $I$ of the electrochemical noise $\mathrm{EN}$. The right hand panel presents selected characteristics of the AE signals for the last two hours of the experiment: (e) energy $E_{\mathrm{AE}}$, (f) duration $t_{\mathrm{AE}}$ and $(\mathrm{g})$ average frequency $f_{\mathrm{PAE}}$. 
In order to be able to better interpret the SCC related characteristics of the AE signals (Fig. 5b), the corresponding elongations $\Delta l$ and electrochemical noise signals, i.e. the electrical potential $U$ and current $I$, are presented in Fig. 5c and d. Additionally, in the diagram showing the stress applied to the specimen (Fig. 5a) some important events such as crack initiation, crack propagation and specimen failure, as detected by the digital CCD camera, are marked. From the diagrams it can be seen that, among the measured signals, the presence of a crack was first detected by the elongation increase $\Delta l$ and by changes in the electrochemical signals $U$ and $I$, soon after second change in the applied tensile stress, at approximately $25.7 \mathrm{~h}$. Based on the cumulative number $N_{\mathrm{AE}}$ of $\mathrm{AE}$ bursts, it is clear that the presence of $\mathrm{AE}$ signals was detected approximately two hours later, i.e. at $27.7 \mathrm{~h}$. At this point in time the experiment the crack was already $2 \mathrm{~mm}$ long, with a surface opening of $0.2 \mathrm{~mm}$, which was estimated by digital imaging of the specimen surface [36]. It was proposed in Ref. [36] that at the time of the observed rise in AE activity the stress due to the reduced cross section was high enough so that some ductile fractures of the ligaments which stayed behind the intergranular advancing crack occurred on the more resistive grain boundaries. Ductile fractures of ligaments cause fast relaxation of elastic energy, and were detected as AE. This AE based observation was confirmed by the simultaneous detection of rapid transients in the electrochemical current noise signal $I$, which are evident in Fig. $5 \mathrm{~d}$. In the right hand panel of Fig. 5 some selected characteristics, i.e. the energy $E_{\mathrm{AE}}$, duration time $t_{\mathrm{AE}}$, and average frequency $f_{\mathrm{pAE}}$ of the detected $\mathrm{AE}$ signals, are additionally shown for the last two hours of the experiment. From these diagrams it is clear that the energy $E_{\mathrm{AE}}$ and the duration time $t_{\mathrm{AE}}$, which are related to signal strength, on average increase with the duration time and crack size (Fig. 5e and f). At the same time the average frequency $f_{\mathrm{pAE}}$ is approximately constant over the entire process of crack propagation and final failure of the specimen (Fig. $5 \mathrm{~g}$ ). This last fact confirms the validity of the assumption that the undergoing processes and the sources of the AE waves which were detected, respectively, during SCC and during final fracture of the specimen, are qualitatively very similar. The only significant differences are in the parameters related to their intensity (amplitude, energy, duration): these parameters are on average considerably higher in the case of final fracture.

\subsection{AE based estimation of the size of the ductile fracture areas}

Additional analysis and characterization of AE signals acquired during different processes, such as ductile fractures during crack growth and specimen failure, were performed in order to investigate the ability of this method to estimate the presence and intensity of these processes. 
In the paper it has already been shown that $\mathrm{AE}$ signals acquired during crack propagation and during final specimen failure have very similar waveforms (Fig. 2a-c). Taking into account this observation, it can be assumed that AE signals acquired during crack propagation, as well as those which occur during failure, are from a similar source, i.e. ductile fracture. This assumption is supported by the similarity of the power spectral density $S_{\mathrm{AE}}$ of AE signals acquired during crack propagation and during specimen failure, as shown inFig. 3a-c. It was also additionally demonstrated by scanning electron microscopy (SEM) of the fracture surface. The results of this analysis showed that the fracture surface of the specimen was approximately $60 \%$ predominantly intergranular, caused by SCC, while the rest of the final fracture surface was ductile, caused by overloading of the specimen due to the reduced cross-section (Fig. 6a). However, in the predominantly intergranular part of the fracture surface some small ductile areas were also observed (Fig. 6b). These areas are in the order of a few $100 \mu \mathrm{m}^{2}$. In [36] it was proposed that these areas developed due to the ductile fracture of ligaments which stayed behind the intergranular advancing crack tip, at more resistant grain boundaries. The number of small ductile areas observed by scanning electron microscopy $\left(N_{\mathrm{dp}}=50\right)$ was approximately the same as the number of $\mathrm{AE}$ signals which were detected after the performed filtering procedure $\left(N_{\mathrm{AE}}=81\right)$, indicating that these AE signals could be related to the ductile fracture process.
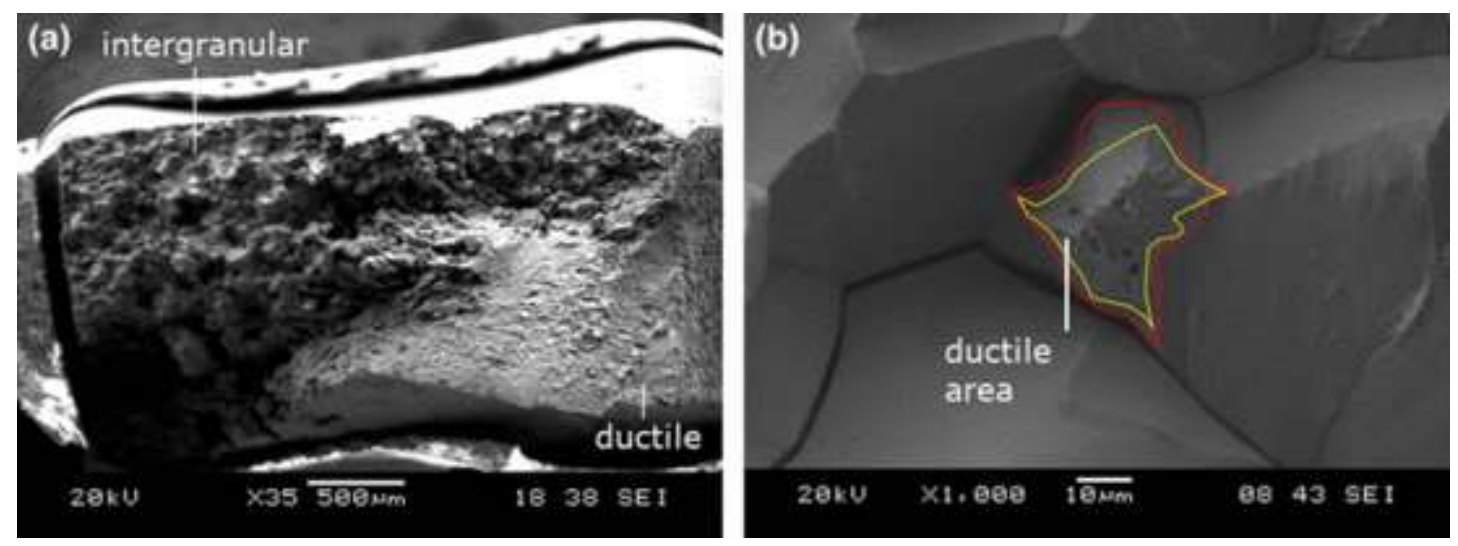

Fig. 6 (a) An example of the final fracture surface of the specimen, (b) the magnified predominantly intergranular part of the final fracture surface, with the example of an individual ductile area in the middle of the image. Two manually defined contours defining the ductile area in widest and narrowest sense are presented to illustrate the accuracy of the area measurement. The large selection is $820 \mu \mathrm{m}^{2}$, while the narrow selection is $560 \mu \mathrm{m}^{2}$ in area.

Based on the presented observations, the energy of the detected $\mathrm{AE}$ signals $E_{\mathrm{AE}}$ was used for estimation of the size of the ductile fracture area. In the case of the considered experiment No.1, within the time interval of the experiment $[27.3,28.8] \mathrm{h}$, where presumably small ductile areas 
were formed in the predominantly intergranular part of the fracture due to crack propagation, the average energy of the AE signals was estimated to be $E_{\mathrm{AEc}}=1.2 \cdot 10^{-1} \mathrm{pJ}$. On the other hand the sum of the energy of all the AE signals captured during specimen failure was approximately $E_{\mathrm{AEF}}=1 \mathrm{~nJ}$. From the SEM analysis of the fracture surface (Fig. 6a) the size of the ductile area of the final fracture surface, caused by failure of the specimen due to overloading, was estimated to be $S_{\mathrm{p}}=3 \mathrm{~mm}^{2}$.Taking into account the quotient of the previously mentioned energies, the average size of an individual ductile fracture area $S_{\mathrm{dpAE}}$ can be estimated as:

$$
\mathrm{S}_{\mathrm{dpAE}}=\left(1.2 \cdot 10^{-1} \mathrm{pJ} / 1 \mathrm{~nJ}\right) 3 \mathrm{~mm}^{2}=0.0004 \mathrm{~mm}^{2} \text {. }
$$

This estimate is in relatively good agreement with the sizes of individual ductile areas (Fig. 6b) visually observed by SEM analysis. Based on the latter the average size of an individual ductile fracture area $S_{\text {dрSEM }}$ was estimated to lie within the interval from $1 \cdot 10^{-4} \mathrm{~mm}^{2}$ to $1 \cdot 10^{-3} \mathrm{~mm}^{2}$. This result shows the ability to use the AE to estimate the source characteristics, in our case the size of the ductile fracture areas. However, no absolute estimation of the size of a ductile fracture area from detected AE signals has yet been performed, and this is a matter for further research.

\subsection{The automatic detection of SCC}

Besides the physical characterization of SCC through an interpretation of corresponding AE signals, the automatic and reliable detection of SCC is of high practical importance. Based on the observed differences of typical waveforms of noise and SCC related AE signals, two independent features were extracted from the AE signals and tested for the purpose of automatic crack detection. One feature is based on a time domain analysis of AE signals, whereas the other is based on a frequency domain analysis.

In the time domain analysis the main feature is the characteristic time $\tau$, which is defined as the time when the amplitude envelope of the AE signal drops from its maximum value to 1/e of that value, where $e \approx 2.71828$ is the base of the natural logarithm. In the case of crack related AE signals a shorter time $\tau$ is characteristic, whereas in the case of noise related AE signals a longer such time $\tau$ is characteristic, as can be clearly seen from Fig. 2. In Fig. 7 values of the characteristic time $\tau$ for different cases are presented and related to the crack state. In order to show that the results were reproducible, the sources of noise and the AE signals of several of the performed SCC experiments (experiments No. 1, 2 and 3) were considered. Here the AE signals are presented from a single AE sensor, yet the results based on the second AE sensor are very similar to the current ones and are thus omitted from the presentation. Furthermore, in order to improve the clarity of the results, the interpretation in each presented diagram, in Fig. 7 the crack non related and crack related AE signals are demarcated by a vertical line, and information about the corresponding 
source of the AE signals or the individual phases of the experiment is provided, in labels, in the diagrams. In the described experiments an optimal threshold value of a characteristic time of $\tau_{\mathrm{b}}=0.6 \mathrm{~ms}$ can be set (this is denoted by the horizontal dotted line in Fig. 7 ) in order to be able to distinguish between crack related and the noise related AE signals. The AE signals with $\tau>0.6 \mathrm{~ms}$ are related to noise, whereas the AE signals with $\tau<0.6 \mathrm{~ms}$ are related to crack propagation or failure of the specimen. From the diagrams it is clear that the defined characteristic time $\tau$ of the AE signal can be fairly reliable used for the detection of crack propagation. Using the extracted time feature $\tau$ of the AE signal, only two AE signals were wrongly classified in the case of experiment No. 3, as can be seen in Fig. 7b. However, these two signals were acquired during loading of the specimen and could be either noise related signals or signals caused by plastic deformation of the specimen. In all the diagrams the last two values of $\tau$ correspond to the $\mathrm{AE}$ signals detected during the specimen failure. Based on these two values, it is clear that there is no significant difference between the crack propagation and specimen failure related characteristic times $\tau$ of the AE signals. 

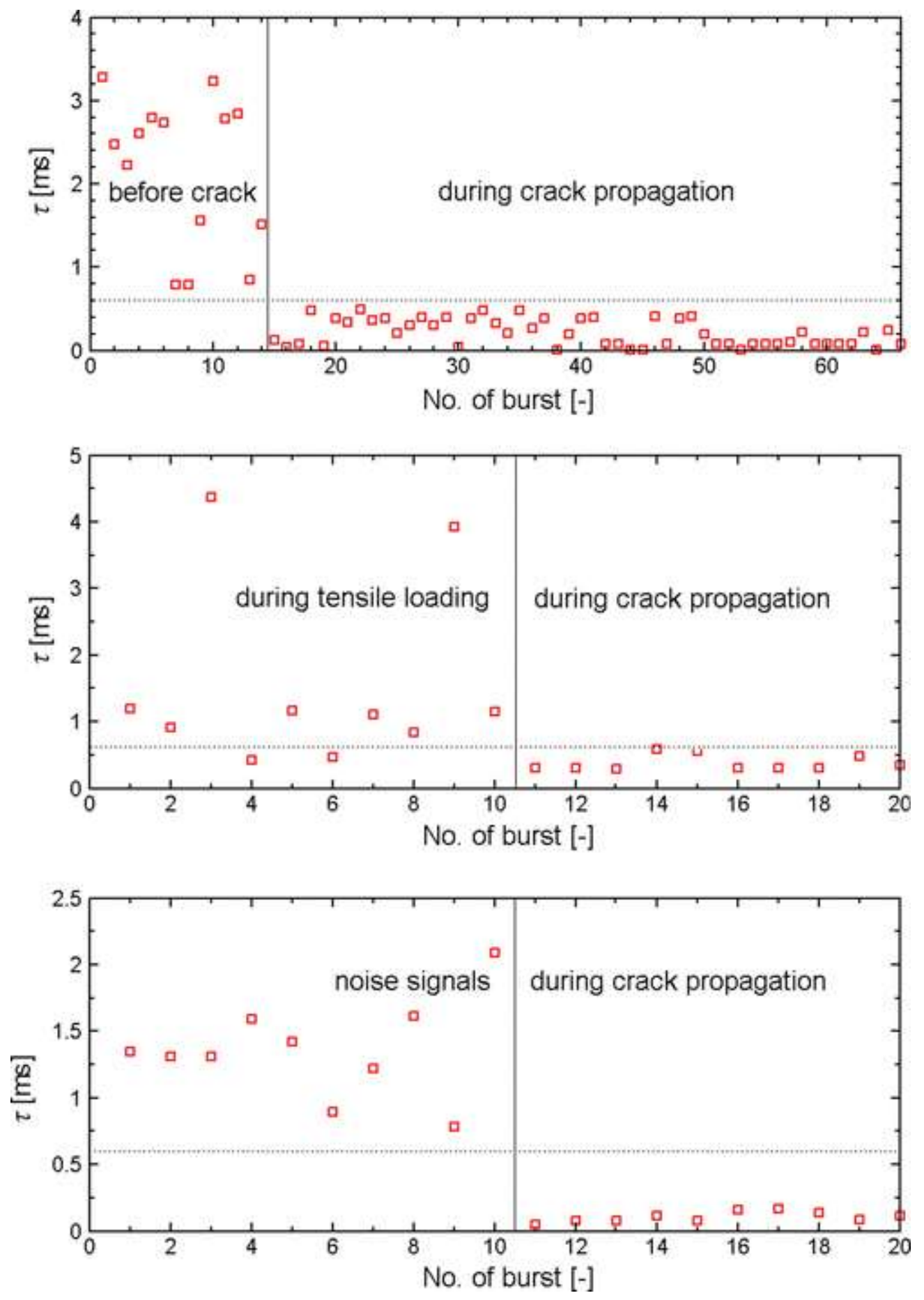

Fig. 7 The characteristic time $\tau$ for sets of AE bursts for the different selected cases related to the crack state: (a) experiment No, 1, sensor 1, (b) experiment No. 3, sensor 1 and (c) experiment No. 2, sensor 1 .

The second feature proposed for automatic SCC detection is based on spectral analysis. As can be seen from the comparison of the power spectra shown in Fig. 3, the crack related AE signals 
have a larger part of power distribution at higher frequencies than the non crack related AE signals. In order to confirm this observation, the power spectra of all $66 \mathrm{AE}$ signals acquired during experiment No. 1 are shown in the spectrogram presented in Fig. 8. Amongst the 66 AE power spectra the first 16 correspond to non crack related AE, whereas the following 50 correspond to crack related $\mathrm{AE}$, and the last two to $\mathrm{AE}$ detected during the specimen failure. Based on the observed power spectra properties, the power spectrum ratio $P=P_{\mathrm{b}} / P_{\mathrm{a}}$ was defined as a feature which could distinguish between crack and non-crack related AE signals. Here, $P_{\mathrm{a}}$ is the power of the spectrum from $0 \mathrm{kHz}$ to $45.8 \mathrm{kHz}$, and $P_{\mathrm{b}}$ is the power of the spectrum from $45.8 \mathrm{kHz}$ to $250 \mathrm{kHz}$. Using the extracted feature $P$, higher values of $P$ are characteristic for crack related AE signals, and lower values for non-crack related AE signals. In Fig. 9 values of the feature $P$ are presented for the same four cases as for the characteristic time $\tau$ shown in Fig. 7. It can be seen from this figure that there is fairly clear difference between the $P$ value of crack not related AE signals, and the $P$ value of crack related AE signals. By setting an optimal threshold value $P=0.7$ a clear detection of crack propagation can be made. Similarly as in the case with the defined time feature $\tau$, only two AE signals are potentially wrongly classified, but again these two signals were acquired during the loading process and could have been caused by plastic deformations which occurred during the loading.

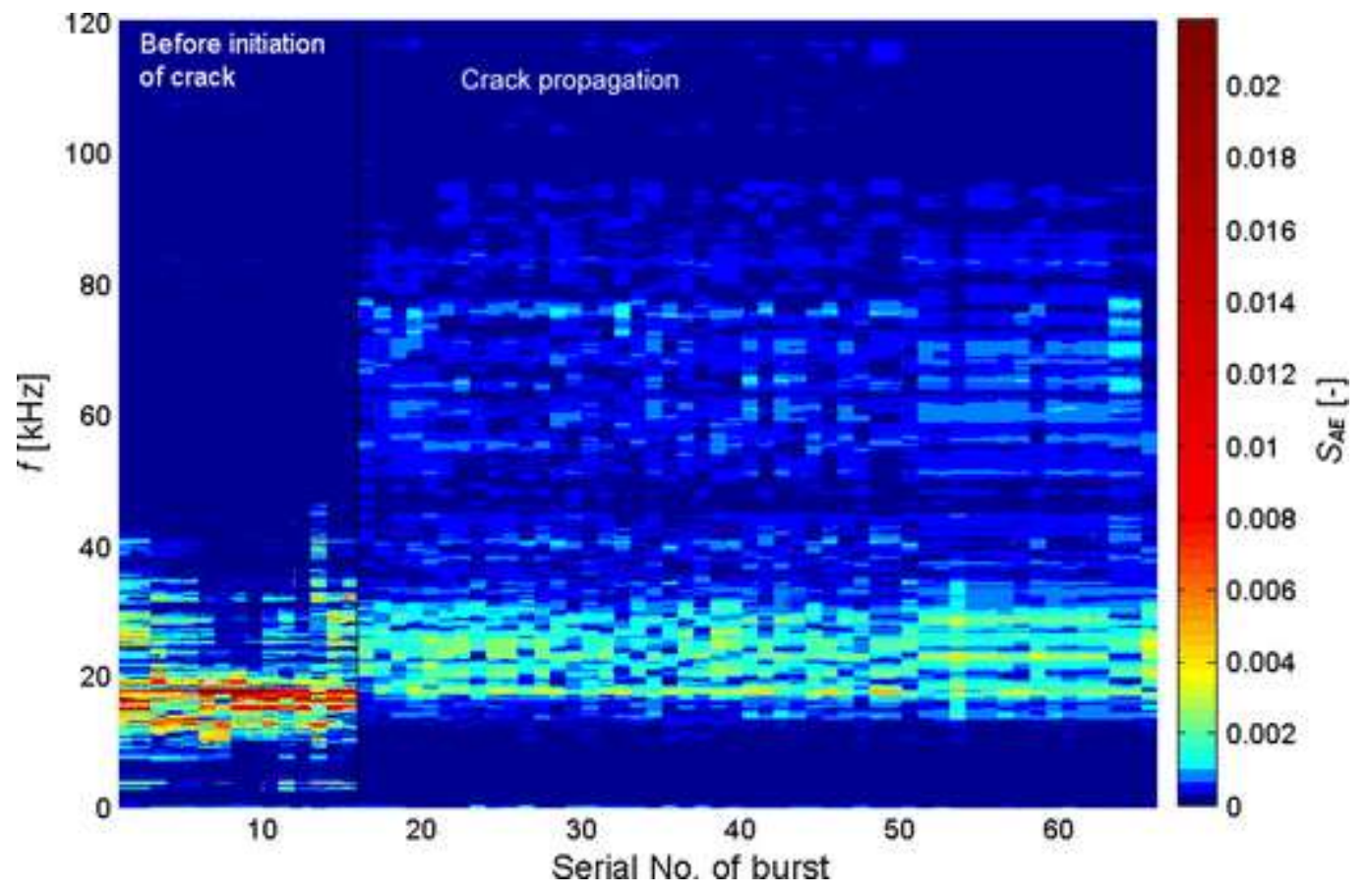

Fig. 8 Spectrogram of 66 AE signals acquired by sensor 1 during experiment No. 1. Power spectra: 1-16 correspond to non crack related AE signals, whereas the power spectra from 17-64 
correspond to the crack propagation period, and the last two power spectra, 65 and 66 , correspond to specimen failure.
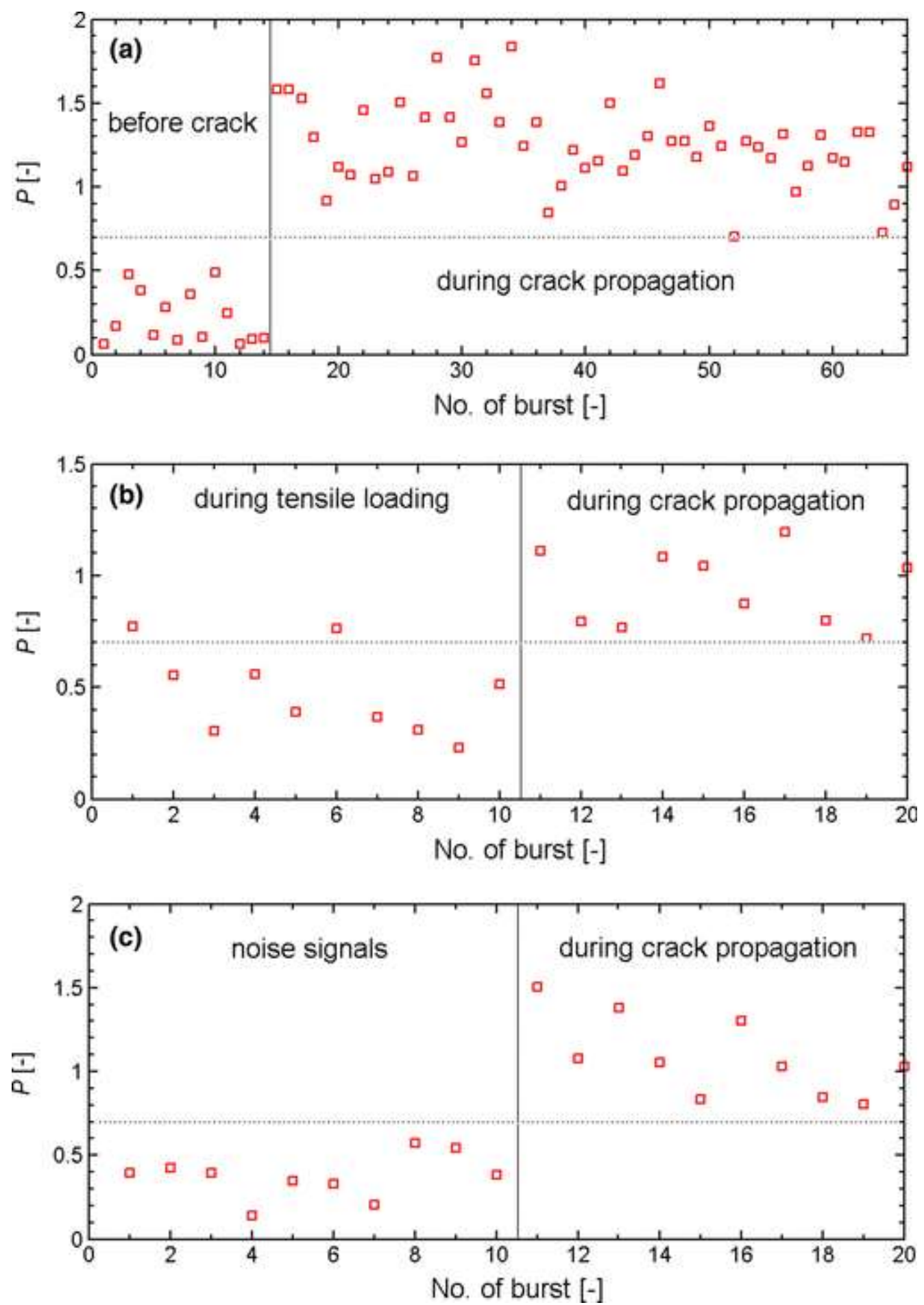

Fig. 9 AE signal power spectra feature $P$ for the different selected cases of non crack related and crack related AE signals: (a) experiment No. 1, sensor 1, (b) experiment No. 3, sensor 1 and (c) experiment No. 2, sensor 1 . 
The automatic filtering as presented above can reliably be used only within a narrow, wellcharacterized set of corrosion conditions most probably including also shape, dimensions and material of the specimen. Additionally, the experimental conditions where motion-related sources (impulse noises such as friction, scratch, and various impacts by foreign objects, that could resulted in similar short duration transient AE signals) are present at the equal distance to both $\mathrm{AE}$ sensors, are not applicable for the presented automatic filtering. The current study is just an attempt to verify whether the crack-related and other (noise) AE signals have sufficiently dissimilar characteristics that would permit their discrimination by a simple computer-based filtering procedure.

\section{Conclusions}

In the paper the results of the $\mathrm{AE}$ based detection and characterization of stress-corrosion cracking (SCC) in stainless steel have been presented. For the purpose of AE signal interpretation, electrochemical noise, specimen elongation measurements, and digital imaging of the specimen surface were also used.

It was shown that there are significant differences between the characteristics of SCC related and crack non related AE signals. The differences are evident in the waveforms and in the corresponding power spectra characteristics of the detected AE signals. Taking this into account, two procedures for the selection of crack related AE signals were introduced: a manual, visual inspection based procedure, and an automatic, time and frequency characteristics based procedure.

The results of the analysis of the SCC related AE signals showed that the AE method is able to detect larger cracks in the case when, apart from intergranular propagation, some small ductile fractures also occur. It has been shown that these ductile fractures are the source of the detected acoustics emission waves. The size of corresponding ductile fracture area can be estimated based on a relative comparison of the energies of the detected AE signals. It has also been shown that AE can be used for the automatic detection of SCC. For this purpose, in addition to the proposed method for the automatic delectation of crack related AE signals, the time and power spectra related features of the detected AE signals were extracted and successfully applied in order to differentiate between SCC related and other crack non related AE signals. A qualitative and quantitative analysis of the detected AE signals and the corresponding power spectra has shown that there is no significant difference between crack propagation and specimen failure AE.

Based on the presented results it can be concluded that AE can be successfully used for SCC detection and characterization in the later phase of this process. For the improvement of the sensitivity of the AE method, further research needs to be performed by providing a less noisy 
environment. The detection and further investigation of AE waves having lower amplitudes could improve the AE detection of SCC at an early stage.

\section{Acknowledgments}

This work was supported by SRA- the Slovenian Research Agency, Research program P2-0273 Building structures and materials and P02-241-Synergetics of complex systems and processes.

\section{References}

[1] R.P. Gangloff and M.B. Ives, (Eds.), Environmental Induced Cracking of Metals, 1990, NACE Publication; Houston.

[2] R.H. Jones, Stress-Corrosion Cracking - Material Performance and Evaluation, 1992, ASM International Materials Park; Ohio.

[3] C. Jirarungsatian and A. Prateepasen, Pitting and uniform corrosion source recognition using acoustic emission parameters, Corros. Sci. 52, 2010,18-197.

[4] K.H.W. Seal, K.B. Lim, C.H. Chew and S.H. Teoh, The correlation of acoustic emission with rate of corrosion, Corros. Sci. 34, 1993, 1707-1713.

[5] Y.P. Kim, M. Fregonese, H. Mazille, D. Feron and G. Santarini, Ability of acoustic emission technique for detection and monitoring of crevice corrosion on 304 austenitic stainless steel, NDT E Int. 36, 2003, 553-562.

[6] A. Arora, Acoustic emission characterization of corrosion reactions in aluminium alloys, Corrosion 40, 1984, 459-465.

[7] F. Ferrer, H. Idrissi, H. Mazille, P. Fleischmann and P. Labeeuw, On the potential of acoustic emission for the characterization and understanding of mechanical damaging during corrosion - abrasion processes, Wear 231, 1999, 108-115.

[8] T.W. Rettig and M.J. Felsen, Acoustic emission method for monitoring corrosion reactions, Corrosion 32, 1976, 121-126.

[9] S. Magaino, A. Kawaguchi, A. Hirata and T. Osaka, Spectrum analysis of corrosion potential fluctuations for localized corrosion of type 304 stainless steel, J. Electrochem.

Soc. 134, 1987, 2993-2996.

[10] R.H. Jones and M.A. Friesel, Acoustic emission during pitting and transgranular crack initiation in type 304 stainless steel, Corrosion 48, 1992, 751-758. 
[11] H. Mazille, R. Rothea and C. Tronel, An acoustic emission technique for monitoring pitting corrosion of austenitic stainless steels, Corros. Sci. 37, 1995, 1365-1375.

[12] M. Fregonese, H. Idrissi and H. Mazille, Monitoring pitting corrosion of AISI 316L austenitic stainless steel by acoustic emission technique: choice of representative acoustic parameters, $J$. Mater. Sci. 36, 2001, 557-563.

[13] M. Fregonese, H. Idrissi, H. Mazille, L. Renaud and Y. Cetre, Initiation and propagation steps in pitting corrosion of austenitic stainless steels: monitoring by acoustic emission, Corros. Sci. 43, 2001, 627-641.

[14] K. Darowicki, A. Mirakowski and S. Krakowiak, Investigation of pitting corrosion of stainless steel by means of acoustic emission and potentiodynamic methods, Corros. Sci. 45, 2003, 17471756.

[15] C. Jirarungsatian and A. Prateepasen, Pitting and uniform corrosion source recognition using acoustic emission parameters, Corros. Sci. 52, 2010,187-197.

[16] Jian Xu, Xinqiang $\mathrm{Wu}$ and En-Hou Han, Acoustic emission during the electrochemical corrosion of 304 stainless steel in $\mathrm{H}_{2} \mathrm{SO}_{4}$ solutions, Corros. Sci. 53 (1), 2011, 448-457.

[17] Jian Xu, Xinqiang Wu and En-Hou Han, Acoustic emission during pitting corrosion of 304 stainless steel, Corros. Sci. 53, 2011, 1537-1546.

[18] R.K. Miller, E. Hill, P.O. Moore (Eds.), Nondestructive Testing Handbook, third ed.: Volume 6, Acoustic Emission Testing, American Society for Nondestructive Testing Inc, Ohio, 2005.

[19] M. Huang, L. Jiang, P.K. Liaw, C.R. Brooks, R. Seeley, D.L. Karstrom, 1998, Using Acoustic Emission in Fatigue and Fracture Material Research, $<$ http://www.tms.org/pubs/journals/JOM/9811/Huang/Huang-9811.html> (approach 08.08.10).

[20] R.C. Newman and K. Sieradzki, Correlation of acoustic and electrochemical noise in the stress corrosion cracking of a-brass, Scripta Metall. Mater. 17 (1983), 1983, 621-624.

[21] P. Lapitz, M.G. Ruzzante and M.G. Alvarez, AE response of -brass during stress corrosion crack propagation, Corros. Sci. 49, 2007, 3812-3825.

[22] M.G. Alvarez, P. Lapitz and J. Ruzzante, AE response of type 304 stainless steel during stress corrosion crack propagation, analysis of acoustic emission signals generated from SCC propagation, Corros. Sci. 55, 2012,5-9. 
[23] H. Okada, K. Yukawa and H. Tamura, Application of acoustic emission technique to the study of stress corrosion cracking in distinguishing between active path corrosion and hydrogen embrittlement, Corrosion 30, 1974,253-255.

[24] H. Okada, K. Yukawa and H. Tamura, Transition of cracking mechanisms from active path corrosion to hydrogen embrittlement in high strength steels in a boiling nitrate solution, Corrosion 32, 1976, 201-203.

[25] J. Kovac, M. Leban and A. Legat, Detection of SCC on prestressing steel wire by the simultaneous use of electrochemical noise and acoustic emission measurements, Electrochim. Acta 52, 2007, 7607-7616.

[26] S. Ramadan, L. Gaillet, C. Tessier and H. Idrissi, Detection of stress corrosion cracking of highstrength steel used in prestressed concrete structures by acoustic emission technique, Appl. Surf. Sci. 254, 2008,2255-2261.

[27] K.Y. Sung, I.S. Kim and Y.K. Yoon, Characteristics of acoustic emission during stress corrosion cracking of Inconel 600 alloy, Scripta Mater. 37, 1997, 1255-1262.

[28] W.W. Gerberich, R.H. Jones, M.A. Friesel and A. Nozue, Acoustic emission monitoring of stress corrosion cracking, Mater. Sci. Eng. A 103, 1988,185-191.

[29] R.H. Jones, M.A. Friesel and R. Pathania, Acoustic emission from intergranular subcritical crack growth, Metall. Trans. A 20A, 1989,637-648.

[30] R.H. Jones, M.A. Friesel and R. Pathania, Evaluation of stress corrosion cracking initiation using acoustic emission, Corrosion 47, 1991, 105-115.

[31] M.G. Alvarez, P. Lapitz and J. Ruzzante, AE response of type 304 stainless steel during stress corrosion crack propagation, Corros. Sci. 50 (12), 2008,3382-3388.

[32] J. Kovac, M. Leban and A. Legat, An attempt to detect SCC by combined measurements of electrochemical noise and acoustic emission, Mater. Corros. 58, 2007, 970-976.

[33] Z. Bajt, M. Bajt Leban, J. Kovac and A. Legat, J. Mech. Eng. 54, 2008,25-36.

[34] R. Van Nieuwenhove and R.-W. Bosch, Acoustic emission detection during stress corrosion cracking at elevated pressure and temperature, J. Acoust. Emission 18, 2000, 293-299.

[35] H. Shaikh, R. Amirthalingam, T. Anita, N. Sivaibharasi, T. Jaykumar, P.Manohar and H.S. Khatak , Evaluation of stress corrosion cracking phenomenon in an AISI type 316LN stainless steel using acoustic emission technique, Corros. Sci. 49, 2007, 740-765. 
[36] J. Kovac, C. Alaux, T.J. Marrow, E. Govekar and A. Legat, Correlations of electrochemical noise, acoustic emission and complementary monitoring techniques during intergranular stresscorrosion cracking of austenitic stainless steel, Corros. Sci. 52, 2010, 2015-2025.

[37] J. Kovač, T.J. Marrow, E. Govekar and A. Legat, Detection and characterisation of intergranular stress-corrosion cracking on austenitic stainless steel, Mater. Corros. 63, 2011, 664-673.

[38] K. Máthis, D. Prchal, R. Novotný and P. Hähner, Acoustic emission monitoring of slow strain rate tensile tests of 304L stainless steel in supercritical water environment, Corros. Sci. 53, 2011, 5963.

[39] A. Yonezu, H. Cho and M. Takemoto, Monitoring of stress corrosion cracking in stainless steel weldments by acoustic and electrochemical measurements, Meas. Sci. Technol. 17, 2006, 24472454.

[40] A. Yonezu, H. Cho, T. Ogawa and M. Takemoto, Simultaneous monitoring of acoustic emission and corrosion potential fluctuation for mechanistic study of chloride stress corrosion cracking, Key Eng. Mater. 321-323, 2006,254-259.

[41] W. Zhang, L. Dunbar and D. Tice, Monitoring of stress corrosion cracking of sensitised 304H stainless steel in nuclear applications by electrochemical methods and acoustic emission, Eng. Mater. Mater. Sci. Eng. Eng. Syst. 3, 2008, 59-71.

[42] G. Du, J. Li, W.K. Wang, C. Jiang and S.Z. Song, Detection and characterization of stresscorrosion cracking on 304 stainless steel by electrochemical noise and acoustic emission techniques, Corros. Sci. 53, 2011, 2918-2926. 